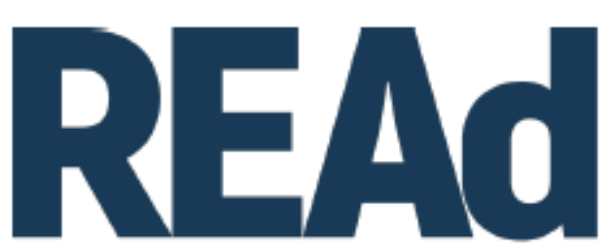

Revista Eletrônica de Administração

\title{
NOVO MODELO E VELHOS PROBLEMAS: A CRIAÇÃO DE UM SERVIÇO SOCIAL AUTÔNOMO SOB A ÓTICA DA EFICIÊNCIA ${ }^{1}$
}

\author{
Bruno Henrique Souza de Andrade ${ }^{2}$ \\ Andréa de Oliveira Gonçalves ${ }^{3}$
}

http://dx.doi.org/10.1590/1413-2311.252.92258

\section{RESUMO}

A pesquisa objetiva analisar os desdobramentos da criação do Instituto Hospital de Base do Distrito Federal (IHBDF) sob a ótica da eficiência do gasto com recursos humanos. Trata-se de uma pesquisa descritiva, com a utilização da Análise Envoltória de Dados (DEA) e a adoção das seguintes variáveis: i) gasto com recursos humanos (GRH); ii) número de cirurgias realizadas (CIR) e iii) número de consultas ambulatoriais realizadas (CSA). A análise abrangeu 240 decision making units (DMUs), que correspondem aos meses observados. Os períodos analisados podem ser segregados em dois grupos: a) modelo tradicional (2008 - 2017), cujos dados foram fornecidos pela Secretaria de Saúde do DF e b) novo modelo (2018 - 2027), o qual abrange os dados projetados. Os resultados evidenciaram que a criação do IHBDF não promove a superação dos denominados velhos problemas, como a ineficiência e a insuficiente oferta de serviços de saúde.

Palavras-chave: Serviço Social Autônomo. Eficiência. Política Pública de Saúde.

\footnotetext{
${ }^{1}$ Recebido em 27/05/2019, aceito em 2/10/2019.

2 Universidade de Brasília - Departamento de Ciências Contábeis Programa de Pós-Graduação em Ciências Contábeis; Brasília - DF (Brasil); http://orcid.org/0000-0002-8251-5539; bhsandrade@gmail.com

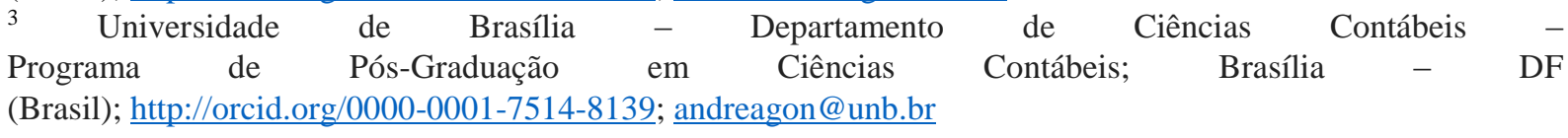




\begin{abstract}
The research aims to analyze the development of the Instituto Hospital de Base do Distrito Federal (IHBDF) from the point of view of the efficiency of human resources expenditure. It deals with a descriptive research, using Data Envelopment Analysis (DEA) and adopting the following variables: i) human resources expenditure (GRH); ii) the number of surgeries (CIR) and iii) the number of outpatient consultations (CSA). The analysis covered 240 decisionmaking units (DMUs), which correspond to the observed months. The analyzed periods can be segregated into two groups: a) traditional model (2008 - 2017), whose data were provided by the Health Department of Distrito Federal and b) new model (2018 - 2027), which covers the projected data. The results showed that the creation of the IHBDF does not promote the overcoming of the so-called old problems, such as inefficiency and the insufficient availability of health services.
\end{abstract}

Key words: Autonomous Social Service. Efficiency. Public Health Policy.

\title{
RESUMEN
}

La investigación objetiva analizar los desdoblamientos de la creación del Instituto Hospital de Base do Distrito Federal (IHBDF) bajo la óptica de la eficiencia del gasto con recursos humanos. Se trata de una investigación descriptiva, con la utilización del Análisis Envoltorio de Datos (DEA) y la adopción de las siguientes variables: i) gasto con recursos humanos $(\mathrm{GRH})$; ii) número de cirugías realizadas (CIR) y iii) número de consultas ambulatorias realizadas (CSA). El análisis abarcó 240 decision making units (DMUs), que corresponden a los meses observados. Los períodos analizados pueden ser segregados en dos grupos: a) modelo tradicional (2008 - 2017), cuyos datos fueron suministrados por la Secretaría de Salud del DF y b) nuevo modelo (2018 - 2027), el cual abarca los datos proyectados. Los resultados evidenciaron que la creación del IHBDF no promueve la superación de los denominados viejos problemas, como la ineficiencia y la insuficiente oferta de servicios de salud.

Palabras clave: Servicio Social Autónomo. Eficiencia. Política Pública de Salud.

\section{INTRODUÇÃO}

(ㄷ) (1) $\left(\right.$ REAd | Porto Alegre - Vol. 25 - N. ${ }^{\circ} 3$ - Setembro / Dezembro 2019 - p. 36 - 61 
O desafio da escolha de modelos no âmbito do sistema público de saúde está intimamente relacionado à discussão sobre os papeis do Estado e ao modelo de administração pública. Nesse sentido, diversas dificuldades atuais dos entes federativos brasileiros enquadram-se no grupo de situações apontadas por Pollitt et al. (2000) com potencial de impulsionar reformas no setor público, como: problemas de ordem financeira, ineficiência da máquina pública, descrédito das organizações públicas e o não atingimento das expectativas dos cidadãos.

No prisma das reformas, constata-se que diversos países, diante das crises no final do século XX, optaram por reduzir o tamanho do Estado e adotaram modelos de administração pública que se espelhassem nas práticas de mercado. Conforme Nunes e Harfouche (2015), o Reino Unido, durante a gestão de Margaret Thatcher, foi quem primeiro introduziu um modelo pautado na busca por eficiência e racionalidade na gestão pública, sobretudo no setor da saúde, o qual foi denominado New Public Management (NPM).

De modo semelhante, no Brasil, iniciou-se um esforço de mudança do modelo de administração pública durante a década de 1990. Entretanto, sua implantação não alcançou o resultado esperado. A esse respeito, Gonçalves et al. (2017) ressaltam que o NPM ainda não pode ser considerado um modelo consolidado no país, porquanto apenas recentemente suas características se mostraram presentes no ambiente das instituições públicas brasileiras.

As diversas formas, estruturas e naturezas jurídicas das organizações de saúde que compõem o Sistema Único de Saúde (SUS) são um retrato da realidade de modelo de administração pública parcialmente implantada. Enquanto em algumas regiões do país a própria administração direta é responsável pela gestão de quase todos os estabelecimentos públicos de saúde, em outras, predominam-se formas alternativas de prestação de serviços, como as baseadas em contratos de gestão.

De acordo com Hortale e Duprat (1999), a lógica contratual está presente em diversos sistemas de saúde estrangeiros. Para Araújo (2005), tal lógica corrobora para o aumento da responsabilização, da qualidade dos serviços oferecidos e, também, com a redução de custos. Por essa razão, esse tipo de modelo tem despertado interesse nos governantes da atualidade. No Distrito Federal, por exemplo, observou-se um intenso debate a respeito da gestão realizada pela própria administração direta versus um modelo baseado em contrato de gestão. O motivo está relacionado à Lei $n^{\circ}$ 5.899/2017, que transformou o Hospital de Base do Distrito Federal (HBDF) em um serviço social autônomo, o Instituto Hospital de Base do Distrito Federal (IHBDF). 
A nova configuração advinda da Lei $n^{\circ} 5.899 / 2017$ produziu uma série de mudanças, de modo que o hospital passou a funcionar nos termos de um contrato de gestão e houve uma alteração em sua natureza jurídica. Esse fato permitiu viabilizar a contratação de empregados pelo regime celetista, assim como, a flexibilização nos processos de compras de materiais e contratações de serviços de terceiros. Entretanto, o governo não divulgou informações que comprovassem os benefícios do novo modelo, sobretudo no que diz respeito aos gastos com recursos humanos.

Diante disso, o objetivo deste artigo é analisar os desdobramentos da criação do Instituto Hospital de Base do Distrito Federal sob a ótica da eficiência do gasto com recursos humanos e, para tanto, desenvolve-se uma métrica para a avaliação da eficiência do gasto com recursos humanos em unidades de saúde.

Além desta introdução, o artigo apresenta seções relacionadas ao referencial teórico, ao percurso metodológico, às análises e discussões dos dados, às conclusões.

\section{A EFICIÊNCIA NO CONTEXTO DA ADMINISTRAÇÃO PÚBLICA}

Em um contexto de regimes absolutistas, como nos séculos VI a XIX no âmbito da Europa, o Estado não poderia ser encarado como algo independente da realeza, ou seja, havia uma junção dos interesses públicos e privados, tratada aqui como uma lógica patrimonialista. O surgimento do modelo tradicional de administração pública que, de modo geral, se consolidou no início do século XX, está relacionado ao anseio de combater tal lógica, uma vez que esta propicia o clientelismo e a corrupção (FERREIRA, 1996).

A concepção do modelo burocrático está relacionada à dominação racional, que se baseia na legitimidade das ordens estabelecidas por determinadas pessoas cujo poder de ordenar seja proveniente de um sistema de regras racionais (WEBER, 1999). O poder de mando, portanto, não estaria relacionado às pessoas em si, mas ao sistema de regras, de modo que aqueles responsáveis pela emissão de ordens estejam também sujeitos a esse sistema.

O modelo burocrático exige que os funcionários possuam uma formação profissional especializada, que suas atribuições estejam formalizadas contratualmente e que respeitem uma hierarquia baseada em cargos. Além disso, tais funcionários devem agir de maneira impessoal, sem influências sentimentais ou pessoais, prezando pela formalidade e o cumprimento das regras racionais (VASCONCELOS, 2004). Assim, o sistema de regras exerce um papel fundamental nesse modelo, pois limita tanto a autoridade daqueles que exercem cargos hierarquicamente superiores, desempenhando alguma função gerencial, 
quanto às atividades dos que atuam em cargos correspondentes aos níveis hierárquicos mais baixos.

No contexto governamental, as organizações burocráticas recebem determinadas atribuições e têm por finalidade continuar executando as mesmas atribuições durante um longo período. Haveria, portanto, um acúmulo de expertise decorrente da repetição que, segundo a lógica weberiana, resultaria em eficiência para a organização (LANE, 2002). Em outras palavras, a especialização na realização de determinadas tarefas levaria a um aperfeiçoamento, sendo que esse aperfeiçoamento não advém da adoção de práticas inovadoras que estejam em desconformidade com o sistema de regras, mas do ganho de expertise na realização daquelas inseridas em tal sistema.

\begin{abstract}
A razão decisiva do avanço da organização burocrática sempre foi a sua superioridade puramente técnica sobre qualquer outra forma. A relação entre um mecanismo burocrático plenamente desenvolvido e as outras formas é análoga à relação entre uma máquina e os métodos não-mecânicos de produção de bens. Precisão, rapidez, univocidade, conhecimento da documentação, continuidade, descrição, uniformidade, subordinação rigorosa, diminuição de atritos e custos materiais e pessoais alcançam o ótimo numa administração rigorosamente burocrática (especialmente monocrática) exercida por funcionários individuais treinados, em comparação a todas as formas colegiais ou exercidas como atividade honorária ou acessória (WEBER, 1999, p. 212).
\end{abstract}

O exemplo de Max Weber (1999), da relação entre o emprego de máquinas e métodos não mecânicos de produção para comparar o modelo burocrático com as outras formas de administração, reflete sua visão a respeito da forma ideal de produção de bens e serviços pelas organizações públicas. Assim, da mesma forma que a mecanização do processo de produção em uma indústria resultaria em uma maior eficiência técnica para a organização, Weber considera que o modelo burocrático garante a otimização na relação entre inputs e outputs.

Matos e Lima (2007) afirmam que a adoção do modelo burocrático pelas organizações modernas ocorreu, sobretudo, em virtude das características técnicas desse modelo. Nesse contexto, o formalismo assume uma posição de destaque, já que o sistema de regras é responsável por dar suporte a todo o processo de produção na lógica do modelo burocrático. Assim, o rigor na busca pela obediência às regras torna possível, sob a ótica burocrática, a otimização da eficiência por parte das organizações.

Dessa forma, constata-se um raciocínio pautado na relação entre a adoção de processos adequados e o atingimento da eficiência. Portanto, o controle de tais processos possui um papel de destaque no modelo burocrático (VASCONCELOS, 2004), posto que a otimização dos resultados depende da sua correta realização. Entretanto, alguns críticos do modelo 
burocrático apontam essa concepção de foco nos processos como um de seus maiores problemas.

Para Merton (1967), tal problema está relacionado a um deslocamento de objetivo. A obediência às regras, que deveria ser um meio, torna-se um fim, transformando-se em um valor imediato, sem que sua finalidade específica seja realmente vista no contexto da organização. Esse processo promove uma exagerada rigidez, impossibilitando a organização de se modificar ou se ajustar em situações nas quais isso seja necessário. Por outro lado, as transformações frequentes e atuais da sociedade criam demandas por mudanças no âmbito do setor público, obrigando com que as organizações públicas se adaptem às necessidades dos cidadãos. Logo, essa disfunção do sistema burocrático apontada por Merton representaria um obstáculo à eficiência organizacional.

Outra crítica ao modelo burocrático diz respeito à sua ineficiência em relação aos custos, em decorrência do ambiente protegido em que as organizações burocráticas estão inseridas. Assim, considerando tais organizações como aquelas dependentes de recursos governamentais e integrantes da estrutura do governo, tende a existir uma proteção delas frente às pressões de mercado em razão da ausência de competição. Por essa razão, é provável que apresentem uma ineficiência em termos de custos, o que produz folgas (slacks) de eficiência, resultando em custos unitários mais altos (LANE, 2002).

Todavia, foi na década de 1970 que essas críticas ao modelo burocrático ganharam mais força, visto que a crise fiscal evidenciou a necessidade de os governos reduzirem seus gastos e otimizarem sua produção de bens e prestação de serviços, o que impulsionou tanto as reformas na concepção de modelo de Estado, quanto as de modelo de administração pública. Nesse contexto, observa-se que as iniciativas que surgiram objetivando mudanças na administração pública possuem uma relação com a ideia de racionalismo econômico, ou seja, fundamentam-se em cálculos econômicos visando a solucionar os problemas no âmbito governamental (SILVESTRE, 2010).

A fim de analisar as características dos modelos burocrático e gerencial e, abordar a forma como a eficiência pode ser enxergada em cada um deles, enfatiza-se que os conceitos e características referentes ao modelo gerencial tratados aqui estarão relacionados especificamente ao New Public Management (NPM). Para Hood (1998), o NPM pode ser considerado tanto um movimento quanto uma área de estudo que impulsionou mudanças no modelo de administração pública burocrático, fazendo o governo adotar um viés empresarial (businesslike) e imputando maior destaque para o papel dos gestores. 
Kettl (2006) afirma que tal movimento faz parte de uma revolução global no âmbito de gestão, da qual poucos governos ficaram imunes. Nesse contexto, o autor estabelece seis componentes que fundamentam o NPM:

a) Produtividade - Vincula-se à necessidade de os governos entregarem mais serviços dada uma quantidade igual ou menor de receita;

b) Marketização - Traduz-se no uso de incentivos de mercado pelo governo, como a privatização, a terceirização e a parceria com instituições não-governamentais para a entrega de serviços públicos;

c) Orientação para serviços - Relaciona-se com a tentativa de se estabelecer uma melhor conexão com os cidadãos, construindo programas não do ponto de vista dos que trabalham para o governo, mas da perspectiva dos cidadãos, colocando-os em primeiro lugar;

d) Descentralização - Resume-se na transferência de responsabilidade de diversos programas para níveis mais baixos de governo, visando a alcançar mais efetividade e garantir uma adequada responsabilização;

e) Política - Refere-se ao objetivo de melhorar a capacidade de elaboração e acompanhamento de políticas, de modo a alcançar maior eficiência na prestação dos serviços;

f) Accountability - Diz respeito à utilização de sistemas bottom-up, orientados para resultados, em vez de sistemas top-down, baseados em regras, a fim de que o governo possa melhorar sua habilidade de entregar aquilo que prometeu.

Tendo em vista esses seis componentes, torna-se evidente o apelo trazido pelo NPM no sentido de produzir mais e melhor ao menor custo possível. Assim, conforme Hood (1991), o NPM é uma expressão de valores cuja ênfase está na relação entre os objetivos da organização e os recursos empregados para atingir tais objetivos, os quais são denominados pelo autor como valores tipo Sigma. Nesse sentido, é inequívoco a relevância do controle sobre os resultados das políticas públicas no âmbito do NPM (SECCHI, 2009), em razão de a mensuração e o acompanhamento dessas políticas só ser viável se existirem mecanismos de controle adequados.

Segundo Silvestre (2010), o desenvolvimento do movimento NPM iniciou-se com a reforma originada no Reino Unido a partir do governo Thatcher em 1979. Nesse contexto, o autor aponta o papel fundamental de elementos como o managerialismo e a marketização para a execução de tal reforma. $\mathrm{O}$ primeiro, diz respeito à tentativa de adotar ferramentas e práticas da iniciativa privada no âmbito da administração pública, já o segundo, refere-se à introdução de mecanismos de concorrência e demais incentivos de mercado, objetivando melhorar a eficiência na prestação dos serviços públicos. A esse respeito, Lane (2002) destaca que há 
uma preferência pela produção outhouse no âmbito do NPM, ou seja, o governo tende a delegar a produção a outros atores em vez de utilizar a máquina pública para executá-la.

Assim, sustenta-se que a soma do controle de resultados e da flexibilidade administrativa idealizadas no NPM, inclina-se a fazer do Estado uma organização mais ágil (PIMENTA, 1998). Essa nova dinâmica da administração pública tende a solucionar o problema de deslocamento de objeto apontado por Merton (1967), pois o foco passa para os resultados e não mais os meios, de forma que o rígido controle baseado na obediência às regras dá lugar ao controle dos produtos (outputs) e dos resultados (outcomes).

Tendo isso em vista, constata-se uma diferença significativa na perspectiva de eficiência quando contrastados os modelos burocrático e NPM. O primeiro se baseia na ideia de que a utilização dos recursos adequados aliada à obediência minuciosa aos processos normatizados produzirá eficiência para a organização. Portanto, há essencialmente um foco na eficiência técnica fundamentada no controle dos recursos e dos processos. Já o NPM utiliza uma dinâmica pautada no controle dos produtos e dos resultados, objetivando garantir a otimização da produtividade, dos custos e dos benefícios gerados à população. Desse modo, não existe apenas uma preocupação com a eficiência técnica, mas também quanto à eficiência de custo (cost efficiency) e à efetividade das ações do governo.

\section{PERCURSO METODOLÓGICO}

As análises da pesquisa basearam-se nos scores de eficiência do gasto com recursos humanos e no comportamento das variáveis que foram utilizadas no modelo de Análise Envoltória de Dados (DEA, na sigla em inglês). Tal técnica, que será detalhada posteriormente, fundamenta-se em cálculo matemático derivado do confronto entre insumos (inputs) e produtos (outputs). Assim, buscou-se a formulação de um modelo que pudesse confrontar os gastos com recursos humanos $(\mathrm{RH})$ e variáveis relacionadas à produção hospitalar.

Nesse sentido, utilizou-se como variável de input o total de proventos pagos aos funcionários do hospital, excluídas as verbas de natureza sazonal como o décimo terceiro salário, as horas extras e as férias, ajustando-se os valores ao limite do teto constitucional de cada período. No modelo, tal variável foi denominada de gasto com recursos humanos (GRH). No âmbito dos outputs, foram utilizadas a quantidade de cirurgias (CIR) e a quantidade de consultas ambulatoriais (CSA). A escolha das variáveis que compõem os outputs do modelo está relacionada à necessidade de representar a produção hospitalar por um 
prisma abrangente. Assim, a variável CIR faz parte dos dados relacionados ao Sistema de Informações Hospitalares do SUS (SIH). Já a variável CSA está relacionada ao Sistema de Informações Ambulatoriais do SUS (SIA).

Os dados da pesquisa basearam-se em períodos mensais e limitam-se ao intervalo 2008-2027. Nesse contexto, os dados referentes ao período 2008-2017 foram obtidos por meio de do Sistema Eletrônico do Serviço de Informação ao Cidadão (e-SIC/DF). Já os dados referentes ao período 2018-2027 foram projetados, ou seja, desenvolveu-se uma metodologia para a projeção das variáveis, a qual será detalhada nesta seção.

No que diz respeito à projeção da variável GRH, foram utilizadas as seguintes premissas:

i) A determinação do número de funcionários contratados pelo regime celetista está baseada na quantidade de vagas previstas no Edital $\mathrm{n}^{\circ} 1$ do processo seletivo simplificado para provimento de vagas do $\mathrm{IHBDF}^{4}$, o qual pode ser encontrado no sítio eletrônico do hospital;

ii) A determinação da quantidade de servidores que desejam ser transferidos de hospital está baseada na lista fornecida pela SES-DF, decorrente da demanda realizada via eSIC. No entanto, assumiu-se que continuarão a atuar no hospital aqueles servidores que desejam a transferência de lotação, mas atuam em cargos para os quais não há previsão de contratação de novos funcionários no edital supracitado.

iii) Para se procederem as substituições dos servidores públicos pelos novos funcionários observou-se a carga horária exercida pelos servidores, de modo que os cálculos dos funcionários novos foram realizados respeitando-se a equiparação de carga horária com aqueles que anteriormente ocupavam os postos de trabalho.

Ressalta-se que para a construção da variável GRH foram utilizados os proventos brutos, uma vez que a utilização dos proventos líquidos ensejaria na utilização de verbas indesejáveis para a análise, como empréstimos consignados, o que poderia distorcer os resultados da pesquisa. No entanto, para a utilização dos proventos brutos, foi necessário proceder a um ajuste, o qual está relacionado à limitação da Lei Orgânica do DF no que diz respeito aos salários dos servidores públicos (DISTRITO FEDERAL, 1993). Ou seja, os proventos de tais servidores não ultrapassam o limite estabelecido na Lei Orgânica. Para tanto, existe uma verba no campo das deduções salarias que estorna os valores superiores ao teto da referida lei. Porém, uma vez que foram utilizados na pesquisa os proventos brutos, tal

\footnotetext{
${ }^{4}$ Edital disponível em:

〈http://www.cespe.unb.br/concursos/IHB DF_18/arquivos/ED_1_2018_IHBDF_18 ABERTURA.PDF>
} 
dedução não foi capturada e, por essa razão, foi necessário proceder ao ajuste dos proventos ao teto estabelecido na Lei Orgânica.

Cabe salientar que o valor do teto salarial sofreu reajustes durante a série histórica utilizada na pesquisa. Nesse contexto, os valores correspondentes ao teto utilizados em cada um dos períodos encontram-se na Tabela 1. Para o período 2018-2027 ajustou-se o teto baseando-se na projeção do Índice de Preços ao Consumidor Autônomo (IPCA), a qual será abordada posteriormente.

Tabela 1: Teto salarial aplicável aos servidores públicos do DF

\begin{tabular}{ll}
\hline Período & Valor (em R\$) \\
\hline $01 / 01 / 2008$ a $31 / 08 / 2009$ & $22.111,25$ \\
$01 / 09 / 2009$ a $31 / 01 / 2010$ & $23.216,81$ \\
$01 / 02 / 2010$ a $31 / 12 / 2012$ & $24.117,62$ \\
$01 / 01 / 2013$ a $31 / 12 / 2014$ & $25.323,51$ \\
$01 / 01 / 2015$ a $31 / 12 / 2017$ & $30.471,11$ \\
\hline
\end{tabular}

Fonte: Dados da pesquisa, 2018.

Destaca-se que a delimitação do período 2018-2027 objetivou a construção de uma série na qual a quantidade de observações para o período realizado fosse a mesma para o período projetado. Além disso, entende-se ser razoável uma projeção que abranja um período de dez anos, uma vez que o contrato de gestão firmado entre a SES-DF e o IHBDF vigorará por vinte anos.

Tendo isso em vista, elucida-se que os cálculos da projeção de gastos com RH foram realizados a partir dos dados do último período de 2017. Portanto, com base nesses dados, procederam-se os cálculos referentes às substituições de servidores públicos por funcionários do IHBDF, a contratação de novos funcionários do IHBDF e a atualização salarial dos servidores públicos e dos funcionários contratados pelo Instituto.

Os procedimentos relacionados às substituições e às novas contratações fundamentaram-se no confronto entre a lista de servidores que desejam a mudança de lotação e o edital do processo seletivo para o IHBDF. Nos casos em que o edital do processo seletivo previu para determinado cargo uma quantidade maior de contratações do que o número de servidores que desejam a mudança de lotação, a quantidade remanescente não foi incluída no grupo de substituições, mas sim naquele relativo às novas contratações. A Tabela 2 demonstra o quantitativo de substituições e de novas contratações utilizadas no cálculo da projeção.

\section{Tabela 2: Número de substituições e novas contratações para a série projetada}




\begin{tabular}{lccc}
\hline \multicolumn{1}{c}{ Cargos } & Substituições & $\begin{array}{c}\text { Novas } \\
\text { Contratações }\end{array}$ & $\begin{array}{c}\text { Total de } \\
\text { Contratações }\end{array}$ \\
\hline Cargo 1: Enfermeiro & 76 & 52 & 128 \\
Cargo 2: Médico: Cir. do Trauma & 0 & 20 & 20 \\
Cargo 3: Médico: Emergência & 0 & 40 & 40 \\
Cargo 4: Médico: Anestesiologista & 0 & 27 & 27 \\
Cargo 5: Médico: Clínica Médica & 4 & 4 & 8 \\
Cargo 6: Médico: Nefrologia & 1 & 7 & 8 \\
Cargo 7: Técnico de Enfermagem & 393 & 84 & 477 \\
\hline Total & $\mathbf{4 7 4}$ & $\mathbf{2 3 4}$ & $\mathbf{7 0 8}$ \\
\hline
\end{tabular}

Fonte: Dados da pesquisa, 2018.

O edital referente ao processo seletivo para o IHBDF prevê para os funcionários uma carga horária de 20 horas semanais, contudo indica que tal carga horária poderá ser majorada. Desse modo, para o quantitativo referente às novas contratações, foi considerado o salário previsto no edital referente à jornada de 20 horas semanais. Já para o caso das substituições, calculou-se um salário para os novos funcionários contratados compatível com a carga horária realizada pelos servidores públicos que estão sendo substituídos.

Uma vez que a lista dos servidores que desejam a mudança de lotação não traz a identificação dos mesmos, utilizou-se o critério de aleatoriedade para a escolha daqueles que seriam substituídos. Assim, a escolha de todos os 474 servidores a serem substituídos foi realizada por meio da fórmula 'ALEATÓRIOENTRE' do Microsoft Excel, respeitando-se a escolha dos cargos e excluindo-se eventuais repetições derivadas da escolha aleatória. A relação da carga horária realizada pelos servidores públicos substituídos de cada cargo encontra-se na Tabela 3.

Tabela 3: Carga horária segregada por cargos dos servidores substituídos

\begin{tabular}{lcccc}
\hline \multirow{2}{*}{ Cargos } & \multicolumn{4}{c}{ Carga horária semanal } \\
\cline { 2 - 5 } & $\mathbf{2 0 h}$ & $\mathbf{2 4 h}$ & $\mathbf{4 0 h}$ & Total \\
\hline Enfermeiro & 22 & 0 & 54 & 76 \\
Médico - Clínica Médica & 4 & 0 & 0 & 4 \\
Médico - Nefrologia & 1 & 0 & 0 & 1 \\
Técnico de Enfermagem & 234 & 67 & 92 & 393 \\
\hline
\end{tabular}

Fonte: Dados da pesquisa, 2018.

O edital do processo seletivo para o IHBDF fornece o valor dos salários referentes a uma jornada de 20 horas semanal, como já referido. Desse modo, no caso dos cargos de enfermeiro e técnico de enfermagem, foi necessário realizar ajustes na projeção dos salários 
de alguns funcionários, tendo em vista a existência de servidores públicos substituídos que possuíam uma jornada de trabalho superior às 20 horas semanais.

Realizados os procedimentos concernentes às substituições e contratações de novos funcionários, foram definidos os critérios para os reajustes salariais na série projetada. Nesse sentido, optou-se por realizar um reajuste anual pelo IPCA acumulado nos últimos 12 meses no mês de janeiro de cada um dos anos projetados. Esses reajustes foram iniciados em janeiro de 2019 e abarcaram tanto os servidores públicos que permaneceram no hospital quanto os novos funcionários contratados.

Assim, em janeiro de 2019 utilizou-se o IPCA projetado para 2018, a fim de se reajustar os salários. Para cada um dos outros períodos, manteve-se a mesma regra, de modo que em janeiro de 2027 utilizou-se o IPCA projetado para 2026. Tais projeções do IPCA estão alicerçadas em Resoluções do Banco Central do Brasil (BACEN), entretanto as mesmas não abarcam todo o período projeto e, portanto, optou-se por utilizar a meta prevista para 2020 nos anos 2021 em diante. Ou seja, a Resolução n 4.582 prevê metas até o ano de 2020, mas a mesma foi utilizada como base para o estabelecimento do IPCA nos anos subsequentes. Desse modo, considerou-se uma tendência de estabilidade em termos de inflação para os períodos não abarcados pelas resoluções do BACEN.

Outro aspecto a ser ressaltado é o fato de o teto que limita os salários dos servidores públicos ter sido utilizado, também, para ajustar os salários da série projetada. Entretanto, visando a manter uma coerência, reajustou-se o valor desse teto pelas mesmas regras utilizadas para os reajustes salariais. Ou seja, os critérios envolvendo o uso do IPCA foram aplicados similarmente na definição do teto salarial para o período projetado.

No que diz respeito aos outputs do modelo, tem-se que a projeção das variáveis CIR e CSA para o período 2018-2027 foram baseadas nas metas evidenciadas no contrato de gestão. Para tanto, optou-se pela utilização do cenário mais otimista em termos de produção, o qual representa o intervalo entre $90 \%$ e $100 \%$ do atingimento das metas de produção. Com o objetivo de se construir uma projeção que considera um aumento progressivo na produção do hospital, adotou-se um crescimento da produção hospitalar entre o primeiro período projetado e o último, dentro do intervalo descrito no contrato de gestão. Assim, no período janeiro/2018 as variáveis CIR e CSA equivalem a 90\% da meta de produção mensal. Tal produção aumenta ao longo dos períodos projetados, de modo que em dezembro/2027 as variáveis em questão assumem o valor correspondente a $100 \%$ da meta.

Concluída a etapa de projeção das variáveis, utilizou-se o modelo DEA para calcular os scores de eficiência, o qual pode ser definido como um método não paramétrico que utiliza 
programação matemática de otimização para determinar a curva de eficiência (PEÑA, 2008). Ressalta-se que a eficiência calculada por meio do DEA nesta pesquisa corresponde ao conceito de eficiência de custo (cost efficiency), em que se propõe o contraste entre uma variável financeira relacionada aos gastos com recursos humanos (GRH) e outras duas variáveis que refletem a produção hospitalar (CSA e CIR).

Para gerar o indicador de eficiência, adotou-se o software DEAP versão 2.1, em razão de seu acesso gratuito e pelo fato de já ter sido utilizado em outras diversas pesquisas (ABBOTT; DOUCOULIAGOS, 2003; KÖKSAL; AKSU, 2007; SONG et al., 2015; TORABIPOUR et al., 2014 ). No que diz respeito aos aspectos operacionais do software, destaca-se que cada período foi considerado uma decision making unit (DMU), uma vez que a análise abrange um único hospital e 240 períodos. Metade desses períodos é constituída de dados realizados e representa o modelo tradicional de prestação de serviços. A outra metade, refere-se a dados projetados e representa a fase concernente ao modelo SSA, também denominado de novo modelo nesta pesquisa.

No que diz respeito aos parâmetros utilizados, optou-se pela escolha de orientação para os inputs, em decorrência de o foco do modelo estar relacionado aos gastos com RH. Além disso, foram escolhidos retornos variáveis de escala (VRS - Variable Returns to Scale) em vez de retornos constantes de escala (CCR - Constant Returns to Scale). Segundo Bahrami et al. (2018), o modelo VRS é necessário em situações em que mudanças nas variáveis de input não produzem mudanças semelhantes nas variáveis de output ou quando há diferenças de tamanho entre as DMUs escolhidas. Nesse sentido, considera-se que as diminuições na variável GRH podem não repercutir da mesma maneira no comportamento das variáveis CSA e CIR, porquanto a criação do IHBDF busca fomentar a redução do gasto com RH e, ao mesmo tempo, o aumento da produção hospitalar. Por isso, optou-se pelo modelo VRS.

Cabe frisar que, no modelo DEA utilizado, não foram atribuídos pesos às variáveis de output. Isso se justifica pelo fato de não terem sido encontrados dados que pudessem servir adequadamente como balizadores da relação entre o gasto com recursos humanos e as variáveis CSA e CIR. Na literatura, alguns trabalhos utilizam os valores da Tabela SUS para propósitos semelhantes. Porém, tendo em vista que o foco da análise é a eficiência do gasto com recursos humanos e não a eficiência do gasto total e considerando os diversos problemas relacionados aos valores provenientes da Tabela SUS (ALMEIDA et al., 2010; BAHIA, 2008; BRACCO et al., 2009), julgou-se mais adequado optar pela não utilização de pesos no modelo DEA. 
Os scores de eficiência foram inicialmente segregados em três categorias distintas, como na pesquisa de Fonseca e Ferreira (2009), visando a permitir uma visualização do comportamento dos scores de eficiência ao longo da série analisada. As categorias utilizadas foram as seguintes: i) desempenho baixo; ii) desempenho médio e iii) desempenho alto.

A categoria 'desempenho alto' foi formada por períodos que alcançaram um score de eficiência maior ou igual à média aritmética somada ao desvio padrão, ou seja, valores maiores ou iguais a 0,953 . Já a categoria 'desempenho baixo', representou os períodos que apresentaram scores iguais ou menores à média aritmética subtraída pelo desvio padrão, o que corresponde a scores menores ou iguais a 0,786. Por fim, a categoria 'desempenho médio' compreendeu os períodos que apresentaram scores maiores que 0,786 e menores que 0,953.

\section{ANÁLISE E DISCUSSÃO DOS RESULTADOS}

A comparação dos resultados de eficiência do gasto com RH nos períodos anteriores e posteriores à criação do serviço social autônomo IHBDF baseou-se em análises fundamentadas na utilização de três categorias de desempenho e na média aritmética dos scores de desempenho.

Nesse sentido, foi primeiramente analisada a frequência (quantidade de meses) das três categorias de desempenho entre os anos de 2008 e 2027. Para tanto, construiu-se o Gráfico 1, o qual evidencia a frequência dos scores de cada período, segregando-os nas categorias 'desempenho baixo', 'desempenho médio' e ‘desempenho alto'.

\section{Gráfico 1: Distribuição de frequências segregadas por períodos}

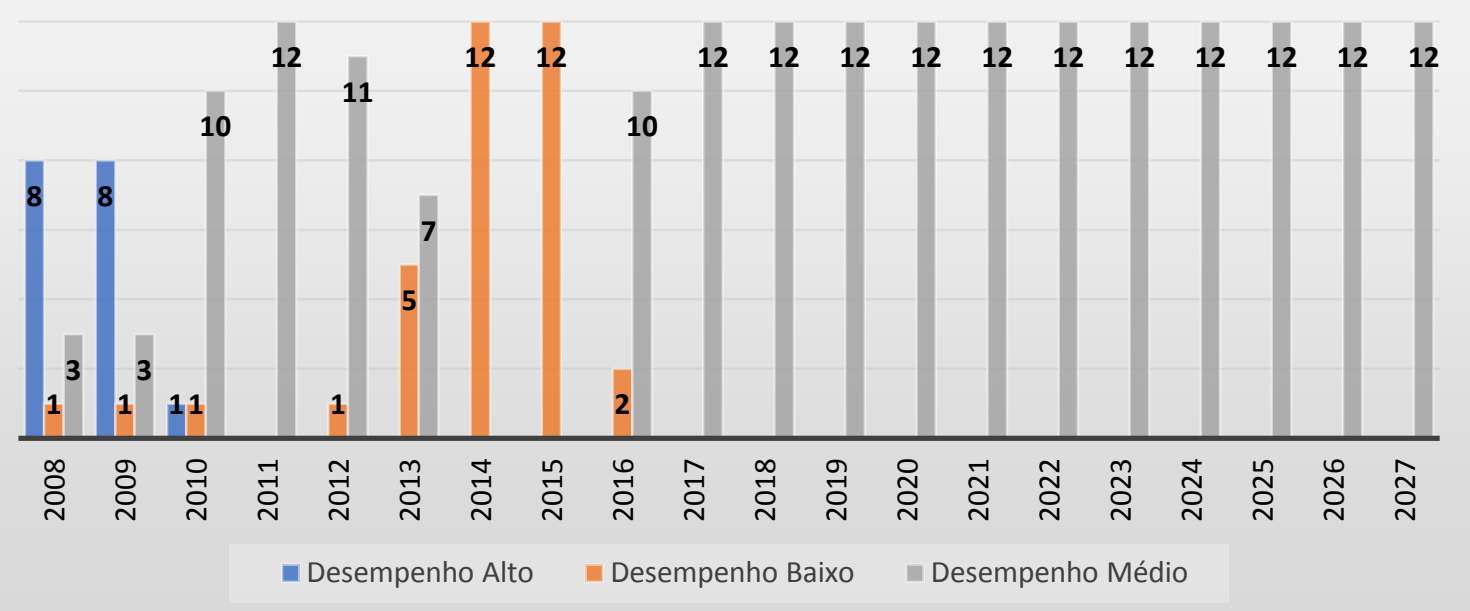

Fonte: Dados da pesquisa, 2018. 
O Gráfico 1 demonstra que os períodos com scores mais altos de eficiência situam-se no início da série. Nesse sentido, apenas os anos de 2008, 2009 e 2010 apresentam períodos que se enquadram na categoria 'desempenho alto'. Nesse contexto, constata-se um cenário em que os períodos projetados não correspondem aos scores de eficiência do gasto com RH mais elevados da série. Ou seja, os maiores scores de eficiência pertencem à fase correspondente ao modelo tradicional e não ao novo modelo.

Um segundo ponto relevante é o fato de todos os períodos de 2014 terem apresentado baixos scores de eficiência, embora a situação emergencial no âmbito da saúde pública do DF tenha iniciado apenas em 2015 (DISTRITO FEDERAL, 2015). Entretanto, o fato de 2014 não estar incorporado aos períodos de situação emergencial no âmbito da saúde DF não significa a inexistência de problemas na prestação dos serviços de saúde em tal período. Destarte, diversas variáveis podem ter contribuído para que não se expusesse a situação desfavorável no âmbito da saúde pública no período em questão. Entre elas, destaca-se, por exemplo, o fato de terem ocorrido eleições para o executivo e o legislativo do DF em 2014.

Para realizar a comparação entre os scores de eficiência de cada período, julga-se necessário verificar o comportamento dos mesmos ao longo da série. No entanto, tendo em vista que tal série é composta por 240 observações, considerou-se adequado calcular o score mensal médio de eficiência em cada ano. Nesse sentido, o Gráfico 2 apresenta o comportamento da média mensal de eficiência do gasto com RH no período 2008 - 2027 .

\section{Gráfico 2: Média mensal dos scores de eficiência anual no período 2008 - 2027}

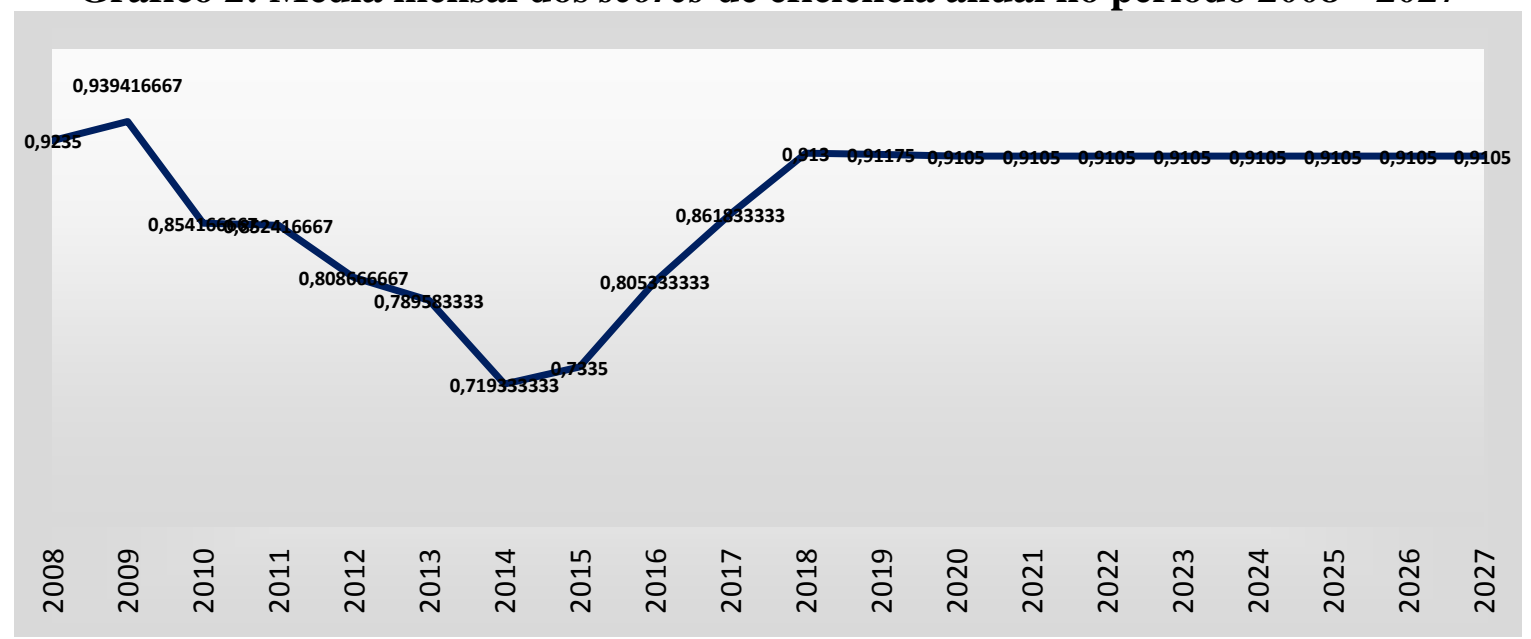

Fonte: Dados da pesquisa, 2018.

Por meio do Gráfico 2, depreende-se que as médias de eficiência mais elevadas se encontram nos períodos iniciais da série. Entretanto, após 2009, é possível observar uma tendência de queda, que perdura até 2014, ano em que se observa a menor média de 
eficiência. Posteriormente, entre os anos de 2015 e 2017, período em que vigorou a situação emergencial no âmbito da saúde pública do DF, contata-se um aumento progressivo da eficiência.

A partir de 2018, inicia-se o período correspondente ao novo modelo, no qual é possível verificar uma estabilidade no que tange ao comportamento dos scores médios de eficiência. Se comparados os resultados relacionados ao novo modelo com aquele observado em 2017, constata-se que a criação do IHBDF resulta em um aumento no nível de eficiência do gasto com RH.

No entanto, a eficiência alcançada após o novo modelo não é superior aos períodos iniciais da série. Assim, tendo em vista as variáveis utilizadas no modelo e a metodologia aplicada para se realizar as projeções, observa-se que a criação do IHBDF proporciona níveis de eficiência próximos àquele observados em 2008, não representando um patamar de eficiência inédito, mas propiciando resultados inferiores aos observados nos melhores períodos do modelo tradicional.

Tendo em vista que a ineficiência é apontada como um dos velhos problemas da máquina pública (LANE, 2002), espera-se que modelos baseados na lógica gerencial resultem em um patamar mais elevado de eficiência. Nesse sentido, o discurso acerca dos benefícios derivados da criação do IHBDF presente na exposição de motivos do PL n ${ }^{\circ}$ 1.486/2017 e nos pareceres das comissões da CLDF aponta para a adoção de uma perspectiva businesslike (HOOD, 1998), a qual resultaria na superação de diversos problemas. No entanto, como evidenciado, o novo modelo não soluciona a questão da ineficiência, pois apenas retoma scores próximos aos observados nos períodos iniciais da fase relacionada ao modelo tradicional. Assim, constata-se que o problema dos slacks de eficiência permanece após a mudança de modelo.

Os resultados apresentados concernentes à eficiência foram calculados com base na relação entre as variáveis que representam os inputs e os outputs do modelo. Por essa razão, entende-se que a análise do comportamento dessas variáveis permite uma melhor compreensão acerca dos scores médios de eficiência apresentados no Gráfico 2. A Tabela 4 apresenta os valores médios para cada uma das variáveis do modelo no período 2008 - 2027 . No que diz respeito ao cálculo da média da variável GRH, salienta-se que foram calculados valores reais.

Tabela 4: Média mensal das variáveis utilizadas no modelo DEA Período Input Output 


\begin{tabular}{cccc}
\cline { 2 - 4 } & GRH $(\mathbf{e m ~ R} \mathbf{)})$ & CSA & CIR \\
\hline 2008 & $46.370 .737,24$ & 42.427 & 860 \\
2009 & $42.285 .371,19$ & 39.172 & 807 \\
2010 & $48.997 .290,83$ & 46.259 & 749 \\
2011 & $46.588 .005,12$ & 28.175 & 802 \\
2012 & $48.682 .283,29$ & 20.194 & 711 \\
2013 & $50.094 .860,07$ & 8.581 & 625 \\
2014 & $54.864 .133,71$ & 10.380 & 606 \\
2015 & $53.721 .746,38$ & 7.851 & 515 \\
2016 & $48.880 .420,00$ & 23.897 & 717 \\
2017 & $45.685 .231,71$ & 23.261 & 698 \\
2018 & $43.107 .283,66$ & 23.766 & 699 \\
2019 & $43.162 .834,43$ & 24.003 & 707 \\
2020 & $43.218 .194,75$ & 24.239 & 715 \\
2021 & $43.217 .336,55$ & 24.476 & 722 \\
2022 & $43.216 .478,37$ & 24.713 & 730 \\
2023 & $43.215 .620,20$ & 24.949 & 738 \\
2024 & $43.214 .762,05$ & 25.186 & 745 \\
2025 & $43.213 .903,92$ & 25.422 & 753 \\
2026 & $43.213 .045,80$ & 25.659 & 761 \\
2027 & $43.212 .187,70$ & 25.919 & 769 \\
\hline
\end{tabular}

Fonte: Dados da pesquisa, 2018.

Ao serem contrastadas as informações da Tabela 4 com aquelas do Gráfico 2, observase que os piores resultados em termos de eficiência derivaram da associação entre um elevado gasto com RH e uma baixa produção hospitalar. Além disso, constata-se que os períodos mais eficientes, que compõem o início da série, não são os que apresentam o menor gasto com RH, entretanto em tais períodos se observa uma produção hospitalar elevada.

A análise da média da variável GRH demonstra que a criação do IHBDF promove uma redução do gasto com RH, mesmo com o aumento do número de funcionários. Tal fato decorre da possibilidade de contratação de funcionários pelo regime celetista e da substituição de servidores públicos por tais funcionários. Ou seja, em razão de ser Serviço Social Autônomo, o hospital passa a possuir autonomia nas contratações. Além disso, a remuneração dos funcionários contratados não necessita seguir a tabela de remuneração dos servidores públicos do DF, o que propicia uma redução do gasto com RH. Essa redução, por sua vez, é condizente com os benefícios da produção outhouse (LANE, 2002).

No que diz respeito às variáveis que compõem os outputs do modelo, observa-se que os períodos posteriores à criação do IHBDF apresentam um crescimento da produção hospitalar se comparados ao ano de 2017. No entanto, verifica-se que os resultados 
provenientes do novo modelo são inferiores àqueles observados nos períodos iniciais da série, os quais apresentaram as melhores médias de eficiência do gasto com RH.

Nesse sentido, é necessário rememorar que os dados projetados para as variáveis CSA e CIR foram baseados nas metas de produção do contrato de gestão. Mais especificamente, o cenário utilizado retrata um intervalo que varia entre $90 \%$ e $100 \%$ do cumprimento das metas. Desse modo, constata-se que, mesmo em uma perspectiva otimista de cumprimento das metas de produção, os períodos relacionados ao novo modelo apresentam resultados inferiores aos dos períodos iniciais do modelo tradicional.

No entanto, cabe ressaltar que, no que diz respeito às análises baseadas na eficiência, certamente os resultados provenientes do modelo DEA utilizado possuem limitações. Primeiramente, o modelo produz unicamente resultados relacionados à eficiência. Além disso, a delimitação das variáveis impacta diretamente nos resultados, de modo que a inclusão ou exclusão de determinada variável culminaria, provavelmente, em resultados distintos. Todavia, a pesquisa não se deteve apenas aos resultados de eficiência, apresentando, também, análises complementares, as quais podem ser observadas nos próximos parágrafos.

Se fatores como o crescimento e o envelhecimento da população tendem a produzir uma maior demanda por serviços públicos de saúde, questiona-se o fato de as metas do contrato de gestão não proporcionarem resultados superiores àqueles observados no início da série. Ou seja, suspeita-se que a produção hospitalar do novo modelo não seja suficiente para suprir a demanda por serviços de saúde.

Diante disso, a fim de estimar o comportamento da demanda, foram utilizadas as seguintes informações: i) população total e idosa do DF no período 2010 - 2027, provenientes do sítio eletrônico do Instituto Brasileiro de Geografia e Estatística (IBGE); ii) percentual da população total e idosa beneficiária de planos de saúde no DF no período 2010 - 2017, oriundas dos sítios eletrônicos da Agência Nacional de Saúde Suplementar (ANS) e do IBGE e iii) a série histórica da taxa de desemprego no DF até o ano de 2017 , procedente do sítio eletrônico do Departamento Intersindical de Estatística e Estudos Socioeconômicos (DIEESE). Nesse contexto, a Tabela 5 apresenta dados acerca da população total e do percentual da população idosa do DF com dados projetados até 2027.

Tabela 5: População total e idosa do DF no período 2010 - 2027

\begin{tabular}{cccc}
\hline Período & População Total & População Idosa & $\begin{array}{c}\text { Percentual de } \\
\text { Idosos }\end{array}$ \\
\hline 2010 & 2.639 .212 & 200.181 & 7,58 \\
2011 & 2.681 .052 & 211.805 & 7,90 \\
2012 & 2.722 .198 & 224.162 & 8,23
\end{tabular}




\begin{tabular}{cccc}
2013 & 2.763 .488 & 237.195 & 8,58 \\
2014 & 2.805 .774 & 250.835 & 8,94 \\
2015 & 2.848 .633 & 265.052 & 9,30 \\
2016 & 2.890 .224 & 279.873 & 9,68 \\
2017 & 2.931 .057 & 295.309 & 10,08 \\
2018 & 2.972 .209 & 311.433 & 10,48 \\
2019 & 3.012 .718 & 328.379 & 10,90 \\
2020 & 3.052 .546 & 346.221 & 11,34 \\
2021 & 3.091 .667 & 364.956 & 11,80 \\
2022 & 3.130 .014 & 384.592 & 12,29 \\
2023 & 3.167 .502 & 405.058 & 12,79 \\
2024 & 3.204 .070 & 426.238 & 13,30 \\
2025 & 3.239 .675 & 448.041 & 13,83 \\
2026 & 3.274 .291 & 470.490 & 14,37 \\
2027 & 3.307 .883 & 493.640 & 14,92 \\
\hline
\end{tabular}

No sítio eletrônico do IBGE, os dados que compõem a série projetada se iniciam em 2010 e, por essa razão, a Tabela 5 não apresenta dados de períodos anteriores. Tendo isso em vista, observa-se que entre os períodos que antecedem a implantação do novo modelo (2010 2017) há um crescimento de $11,05 \%$ da população total do DF e de $47,52 \%$ no que diz respeito a sua população idosa. Nota-se, ainda, que no ano de 2027 estima-se que o número de habitantes do DF ultrapasse a marca de 3,3 milhões e que sua população idosa corresponda a $14,92 \%$ desse total.

De acordo com a perspectiva de Lima-Costa e Veras (2003), tais fatos apontam para um aumento da demanda por serviços públicos de saúde no DF. Assim, esse crescimento da demanda gera, consequentemente, a necessidade de haver um aumento de produção nas unidades hospitalares. Por essa razão, considera-se que as metas do contrato de gestão deveriam estar alinhadas com a demanda por serviços de saúde, a fim de se permitir que a população seja atendida de maneira adequada.

Outro fato que sugere um aumento da demanda pelos serviços públicos de saúde é a diminuição, nos períodos recentes, do percentual da população que é beneficiária de planos de saúde. Nesse sentido, a Tabela 6 traz o percentual de beneficiários em relação à população total e à população idosa do DF.

Tabela 6: Percentual de beneficiários de planos de saúde no DF

\begin{tabular}{ccc}
\hline Período & $\begin{array}{c}\text { Percentual de Beneficiários - } \\
\text { População Total }\end{array}$ & $\begin{array}{c}\text { Percentual de Beneficiários - } \\
\text { População Idosa }\end{array}$ \\
\hline 2010 & 24,31 & 41,75 \\
2011 & 25,95 & 39,71
\end{tabular}




\begin{tabular}{ccc}
2012 & 29,40 & 44,40 \\
2013 & 30,36 & 43,44 \\
2014 & 32,62 & 43,94 \\
2015 & 31,77 & 42,63 \\
2016 & 30,79 & 40,68 \\
2017 & 29,55 & 38,50 \\
\hline & Fonte: Sítios eletrônicos do IBGE e da ANS com adaptações, ano.
\end{tabular}

Conforme pode ser observado na Tabela 6 , o percentual da população total e da população idosa do DF que possui plano de saúde tem reduzido desde 2015. Acerca disso, argumenta-se que a elevação da taxa de desemprego possa ter contribuído com a redução do percentual de beneficiários de plano de saúde, pois, de acordo com o Departamento Intersindical de Estatística e Estudos Socioeconômicos (DIEESE), a taxa de desemprego no DF, que era 10,6\% em dezembro de 2012, avançou para 17,9\% em dezembro de 2017. Igualmente, observa-se que os aumentos mais significativos da referida taxa ocorreram a partir de 2015.

Desse modo, defende-se que o aumento populacional no DF, sobretudo da população idosa, somado à redução do percentual de beneficiários de planos de saúde, tende a promover um crescimento da demanda por serviços públicos de saúde. Ou seja, há evidências de que a demanda por serviços públicos de saúde tenha aumentado entre os anos de 2008 e 2017 . No entanto, em termos de produção hospitalar, as metas do contrato de gestão apontam para uma produção inferior à observada em 2008. Desse modo, mesmo que tais metas produzam resultados melhores que aqueles observados nos períodos mais recentes, entende-se que os mesmos não serão suficientes para suprir a demanda pelos serviços de saúde.

Destarte, observa-se um cenário em que o comportamento da produção hospitalar decorrente da criação do IHBDF não atende à lógica do aumento da demanda por serviços públicos de saúde. Assim, as metas de produção do contrato de gestão se mostram insuficientes para a solução dos velhos problemas relacionados à demanda reprimida no hospital e tal fato vai de encontro às garantias constitucionais acerca do direito à saúde (BRASIL, 1988).

Portanto, há um descompasso entre os resultados de produção provenientes da adoção do novo modelo e os preceitos de produtividade relacionados à reforma gerencial, apontados pela literatura (KETTL, 2006). Nesse sentido, a lógica ressaltada por Secchi (2009) concernente ao controle de resultados no âmbito de modelos como o NPM não visa a promover pequenas melhorias na prestação de serviços públicos, mas objetiva garantir a superação de problemas. No entanto, como já abordado, as projeções relacionadas à criação 
do IHBDF demonstram apenas uma melhora na produção, sem que se consiga resolver os problemas da demanda reprimida.

Tendo em vista que as projeções acerca do novo modelo não são coerentes com os benefícios apontados pela literatura do NPM, tem-se um questionamento acerca da motivação dos gestores públicos ao optarem pela implantação desse novo modelo no âmbito do Hospital de Base. A fim de explorar essa questão, utilizar-se-á conceitos como legitimidade, isomorfismo mimético e autointeresse.

A análise do contexto da criação do Instituto revela, no período que a antecede, a existência de uma situação de crise no âmbito da saúde pública do DF. A crise em questão, culminou em problemas no que tange à prestação de serviços e, certamente, provocou insatisfação nos usuários dos serviços em questão. Tais problemas estão, inclusive, evidenciados no relatório de fiscalização do Ministério Público do Distrito Federal e Territórios (MPDFT) em parceria com os conselhos profissionais (MPDFT, 2017).

Se de um lado existe uma situação negativa para o governo em termos de legitimidade, do outro, conforme demonstrado nas análises, nota-se que a adoção do novo modelo não promove níveis disruptivos de eficiência sob a ótica dos recursos humanos. Portanto, levando em consideração as ideias de Suchman (1995), depreende-se que a decisão relacionada à mudança de modelo pode ter sido fomentada pela questão da legitimidade, sem que aspectos relacionados à eficiência assumissem um papel preponderante.

Além disso, sugere-se que a tentativa de se imitar um modelo já utilizado em outro hospital do DF pode, também, ajudar a explicar a decisão dos gestores no tocante à criação do Instituto, conforme as ideias de Dimaggio e Powell (1983) acerca do isomorfismo mimético. Algumas evidências disso podem ser encontradas na exposição de motivos do Projeto de Lei $n^{\circ}$ 1486/2017, que cria o IHBDF. No documento em questão, defende-se que o Hospital Sarah Kubitschek, reconhecido pelos excelentes serviços prestados à população, adota o modelo Serviço Social Autônomo, o qual seria de igual modo adotado pelo Instituto, com o objetivo de sanar os problemas do hospital (DISTRITO FEDERAL, 2017).

Assim, existem elementos que sugerem um processo de mimetização com base no modelo de gestão hospitalar adotado no Hospital Sarah Kubitschek. No entanto, não se observam na argumentação contida na exposição de motivos do Projeto de Lei ressalvas ou ponderações quanto às diferenças em termos de especialidades e número de leitos entre o Hospital Sarah Kubitschek e o Hospital de Base. Assim, não há evidências de que tais diferenças foram consideradas para fins de tomada de decisão. 
A motivação para a criação do IHBDF pode, ainda, estar relacionada à ideia de autointeresse trazida por Jensen e Meckling (1976). Isso porque a mudança no modelo de gestão permite a contratação de novos funcionários sem que o valor gasto com os mesmos entre no cálculo do limite de gasto com pessoal contido na Lei de Responsabilidade Fiscal (BRASIL, 2000). Assim, a mudança do modelo de gestão pode ter sido impulsionada pelo receio, no curto prazo, de se ultrapassar os limites de gasto com pessoal da referida Lei, sem que questões de longo prazo fossem devidamente consideradas. Esse descasamento entre a perspectiva de curto prazo do agente e a de longo prazo do principal pode ser denominado como um problema de horizonte (BYRD; PARRINO; PRITSCH, 1998).

De todo modo, o cerne da questão consiste no fato de as análises desta pesquisa terem demonstrado que o novo modelo é insuficiente para resolver os problemas da ineficiência e da demanda reprimida. Portanto, entende-se que a tomada de decisão acerca da criação do Instituto e da definição de suas metas de produção pode ter sido realizada sem a utilização de informações e estudos adequados. Nesse contexto, os defensores do modelo gerencial de administração pública advogam que, caso não existam informações suficientes para os gestores inferirem sobre os benefícios de determinadas escolhas, ou caso as informações disponíveis não forem confiáveis, haverá uma grande limitação à produção de bons resultados por esses gestores (WARREN; BARNES, 2003).

Assim, evidencia-se a necessidade da criação de mecanismos que exijam a realização de estudos que subsidiem as tomadas de decisão no âmbito do setor público do DF. Tais estudos, por exemplo, poderiam ser parte obrigatória dos Projetos de Lei e conter análises sobre aspectos quantitativos, como o impacto no orçamento, nas finanças públicas e na eficiência do gasto público e, também, qualitativos, como a repercussão na qualidade dos serviços prestados. Dessa forma, a implantação desses mecanismos poderia facilitar o alinhamento entre os interesses dos gestores públicos e dos cidadãos.

\section{CONCLUSÕES}

Em um cenário de problemas de ordem fiscal, observa-se a dificuldade dos governantes em manter o modelo tradicional de prestação de serviços públicos de saúde e, ao mesmo tempo, garantir o direito constitucional à saúde. Diante disso, nota-se o surgimento de arranjos alternativos na prestação de serviços públicos de saúde em diversas regiões do país, os quais, via de regra, baseiam-se em elementos relacionados aos modelos gerenciais de administração pública. 
No Distrito Federal, por exemplo, foi criado por meio da Lei n ${ }^{\circ} 5.899 / 2017$ o Instituto Hospital de Base do Distrito Federal (IHBDF), Serviço Social Autônomo cujo funcionamento está alicerçado na lógica de contratualização. No entanto, não foram apresentados estudos por parte do governo do DF que evidenciassem os benefícios da criação do IHBDF. Diante disso e levando-se em consideração a relevância do controle de gastos com recursos humanos na administração pública, este artigo analisou os desdobramentos da criação do IHBDF sob a ótica da eficiência do gasto com recursos humanos.

Observou-se que, na fase relacionada ao novo modelo, existem apenas scores enquadrados na categoria 'desempenho médio', o que demonstra que a criação do IHBDF não cria um patamar disruptivo de eficiência do gasto com RH, porquanto não supera a eficiência observada nos períodos iniciais da série. A análise das médias aritméticas dos scores em cada um dos anos observados reforça o argumento acima, pois revela que a adoção do novo modelo apenas produz uma melhora dos scores de eficiência em relação aos últimos períodos da fase que abrange o modelo tradicional, sem superar os períodos iniciais da fase em referência.

Além disso, foram identificados problemas relacionados às metas estabelecidas no contrato de gestão, o que acarreta um descasamento entre a produção hospitalar e a demanda por serviços de saúde. As análises demonstraram que o crescimento da população total e da população idosa no DF, somados ao crescimento da taxa de desemprego e à diminuição do percentual da população que possui planos de saúde, apontam para uma tendência de crescimento da demanda por serviços públicos de saúde. Porém, uma vez que o período projetado apresenta resultados da produção hospitalar inferiores aos observados no início da série, nota-se que a oferta de serviços de saúde no hospital não acompanha a lógica do aumento de demanda.

Desse modo, constata-se que a adoção do novo modelo não soluciona os velhos problemas recorrentes na esfera da saúde pública relacionados à ineficiência e à incompatibilidade entre a oferta e a demanda de serviços de saúde. Não se pode, portanto, afirmar que a criação do IHBDF esteja em conformidade com os preceitos de reforma da administração pública apontados pela literatura (HOOD, 1998; LANE, 2002; SILVESTRE, 2010).

No que diz respeito às contribuições da pesquisa, destaca-se o desenvolvimento de uma métrica para a avaliação de modelos alternativos de prestação de serviços públicos de saúde. Ademais, ressalta-se que tal métrica foi utilizada para a avaliação de um serviço social autônomo, criado recentemente no Distrito Federal e objeto de diversas discussões nos canais 
midiáticos. Assim, tendo em vista que a academia possui um papel preponderante na produção de informações e na promoção de discussões relevantes para a sociedade, considerase que os resultados do estudo demonstram utilidade prática, o que vai ao encontro da necessidade apontada por Bogason e Brans (2008).

\section{REFERÊNCIAS}

ABBOTT, Malcolm; DOUCOULIAGOS, Chris. The efficiency of Australian universities: a data envelopment analysis. Economics of Education review, v. 22, n. 1, p. 89-97, 2003.

ALMEIDA, Patty Fidelis et al. Desafios à coordenação dos cuidados em saúde: estratégias de integração entre níveis assistenciais em grandes centros urbanos. Cadernos de Saúde Pública, v. 26, p. 286-298, 2010.

ARAÚJO, Joaquim Filipe. A Reforma do Serviço Nacional de Saúde: o novo contexto de gestão pública. Universidade do Minho, 2005.

BAHIA, Ligia. As contradições entre o SUS universal e as transferências de recursos públicos para os planos e seguros privados de saúde. Ciência \& saúde coletiva, v. 13, p. 1385-1397, 2008 .

BAHRAMI, Mohammad Amin et al. Data envelopment analysis for estimating efficiency of intensive care units: a case study in Iran. International journal of health care quality assurance, v. 31, n. 4, p. 276-282, 2018.

BOGASON, Peter; BRANS, Marleen. Making public administration teaching and theory relevant. European Political Science, v. 7, n. 1, p. 84-97, 2008.

BRACCO, Oswaldo Luis et al. Custo hospitalar para tratamento da fratura aguda do fêmur por osteoporose em dois hospitais-escola conveniados ao Sistema Único de Saúde. J Bras Econ Saude, v. 1, n. 1, p. 3-10, 2009.

BRASIL. Constituição da República Federativa do Brasil de 1988. Disponível em:http://www.planalto.gov.br/ccivil_03/constituicao/constituicaocompilado.htm Acesso em $10 / 12 / 2017$.

BRASIL. Lei Complementar $\mathbf{N}^{\mathbf{0}}$ 101/2000 (Lei de Responsabilidade Fiscal - LRF). Estabelece normas de finanças públicas voltadas para a responsabilidade na gestão fiscal e dá outras providências. Brasília: 2000. Disponível em: http://www.planalto.gov.br/ccivil _03/LEIS/LCP/Lcp101.htm . Acesso em 19 out. 2017.

BYRD, John; PARRINO, Robert; PRITSCH, Gunnar. Stockholder-manager conflicts and firm value. Financial Analysts Journal, v. 54, n. 3, p. 14-30, 1998.

DIMAGGIO, Paul J.; POWELL, Walter W. The iron cage revisited: Institutional isomorphism and collective rationality in organizational fields. American sociological review, p. 147-160, 1983. 
DISTRITO FEDERAL. Decreto $\mathbf{n}^{\mathbf{0}}$ 36.279/2015. Declara a situação de emergência no âmbito da Saúde Pública do Distrito Federal e dá outras providências. Brasília: 2015. Disponível em: https://www.tc.df.gov.br/SINJ/Norma/78903/Decreto_36279_19_01_2015.html Acesso em 22 dez. 2017.

DISTRITO FEDERAL . Lei Orgânica do Distrito Federal de 1993. Disponível em: https://www.cl.df.gov.br/pesquisa-de-leis-e-proposicoes Acesso em 12 set. 2019.

DISTRITO FEDERAL . Projeto de Lei $\mathbf{n}^{\circ}$ 1486/2017. Autoriza o Poder Executivo a instituir o Instituto Hospital de Base do Distrito Federal - IHBDF e dá outras providências. Brasília: 2017. Disponível em: http://legislacao.cl.df.gov.br/Legislacao/consultaProposicao1!1486!2017!visualizar.action Acesso em 12 set. 2019.

FERREIRA, Caio Márcio Marini. Crise e reforma do Estado: uma questão de cidadania e valorização do servidor. Revista do Serviço Público, v. 47, n. 3, p. 5, 1996.

FONSECA, Poty Colaço; FERREIRA, Marco Aurélio Marques. Investigação dos níveis de eficiência na utilização de recursos no setor de saúde: uma análise das microrregiões de Minas Gerais. Saúde e Sociedade, v. 18, p. 199-213, 2009.

GONÇALVES, Andrea de Oliveira et al. Que Modelo é esse? as alterações nos processos de capacitação de recursos humanos nos 20 Anos do Plano MARE. Administração Pública e Gestão Social, v. 9, n. 1, p. 298-309, 2017.

HOOD, Christopher. A public management for all seasons?. Public administration, v. 69, n. 1, p. 3-19, 1991.

HOOD, Christopher. The art of the state: Culture, rhetoric, and public management. Oxford University Press, 1998.

HORTALE, Virginia Alonso; DUPRAT, Philippe. O contrato de gestão na reforma do subsistema hospitalar francês: contribuição à discussão sobre a descentralização dos serviços de saúde no Brasil. Revista de Administração Pública, v. 33, n. 2, p. 7-22, 1999.

JENSEN, Michael C.; MECKLING, William H. Theory of the firm: Managerial behavior, agency costs and ownership structure. Journal of financial economics, v. 3, n. 4, p. 305-360, 1976.

KETTL, Donald F. The global public management revolution. Brookings Institution Press, 2006.

KÖKSAL, Can Deniz; AKSU, A. Akin. Efficiency evaluation of A-group travel agencies with data envelopment analysis (DEA): A case study in the Antalya region, Turkey. Tourism Management, v. 28, n. 3, p. 830-834, 2007.

LANE, Jan-Erik. New Public Management: An Introduction. London: Routledge, 2002. LIMA-COSTA, Maria Fernanda; VERAS, Renato. Saúde pública e envelhecimento. Cad. Saúde Pública. V.19, n.3 p.700-701, 2003.

MATOS, Fátima Regina Ney; LIMA, Afonso Carneiro. Organizações modernas e a burocracia: um a "afinidade eletiva"? Revista de Administração de Empresas da Fundação Getúlio Vargas, vol. 6, n. 2, 2007. 
MERTON, Robert K. Estrutura burocrática e personalidade. In: Etzioni, Amitai. Organizações complexas. 1. Ed. São Paulo. Atlas, 1967. P. 57.

MPDFT - MINISTÉRIO PÚBLICO DO DISTRITO FEDERAL E TERRITÓRIOS.

Relatório final da força-tarefa de fiscalização conjunta dos hospitais públicos do Distrito Federal. Brasília: 2017. Disponível em: http://www.mpdft.mp.br/portal/pdf/noticias /maio_2019/For\%C3\%A7a-Tarefa_para_avalia\%C3\%A7\%C3\%A3o_e_diagn\%C3\%B3stico_ da_for\%C3\%A7a_de_trabalho_da_SES-DF_1.pdf . Acesso em 10 jun. 2018.

NUNES, Alexandre Morais; HARFOUCHE, Ana Paula de Jesus. A reforma da administração pública aplicada ao setor da saúde: A experiência portuguesa. Revista de Gestão em

Sistemas de Saúde, v. 4, n. 2, p. 1, 2015.

PEÑA, Carlos Rosano. Um modelo de avaliação da eficiência da administração pública através do método análise envoltória de dados (DEA). RAC-Revista de Administração Contemporânea, v. 12, n. 1, 2008.

PIMENTA, Carlos César. A reforma gerencial do Estado brasileiro no contexto das grandes tendências mundiais. Revista de Administração pública, v. 32, n. 5, p. 173-199, 1998.

POLLITT, Christopher et al. Agencies: a test case for convergence. In: Fourth International Symposium on Public Management, Erasmus University, Rotterdam. 2000.

SECCHI, Leonardo. Modelos organizacionais e reformas da administração pública. Revista de Administração Pública, v. 43, n. 2, p. 347-369, 2009.

SILVESTRE, Hugo Consciência. Gestão pública: modelos de prestação no serviço público. Lisboa, Escolar Editora, 2010.

SONG, Chenxi et al. A data envelopment analysis for energy efficiency of coal-fired power units in China. Energy conversion and management, v. 102, p. 121-130, 2015.

SUCHMAN, Mark C. Managing legitimacy: Strategic and institutional approaches. Academy of management review, v. 20, n. 3, p. 571-610, 1995.

TORABIPOUR, Amin et al. Hospitals productivity measurement using data envelopment analysis technique. Iranian journal of public health, v. 43, n. 11, p. 1576, 2014.

VASCONCELOS, Flávio Carvalho. Racionalidade, autoridade e burocracia: as bases da definição de um tipo organizacional pós-burocrático. Revista de Administração Pública, v. 38, n. 2, p. 199-220, 2004.

WARREN, K.; BARNES, C. The impact of GAAP on fiscal decision making: A review of twelve yerars'experience with accrual and output-based budgets in new zealand. OECD Journal on Budgeting, v3, n4, 2003, p. 7-40. Disponível em: https://www.oecd.org/ newzealand/43494437.pdf Acesso em 13 Ago. 2018.

WEBER, Max. Economia e sociedade: fundamentos da sociologia compreensiva. $v$. 2. Brasília: UnB, 1999. 